\title{
Efficient Production Monitoring on the Basis of Domain Ontologies by Utilizing IoT
}

\author{
Maha Riad \\ Faculty of Informatics and \\ Computer Science \\ The British University in Egypt \\ Cairo, Egypt \\ riad_maha@hotmail.com
}

\author{
Amal Elgammal \\ Faculty of Computers and \\ Information \\ Cairo University \\ Cairo, Egypt \\ a.elgammal@fci-cu-edu.eg
}

\author{
Doaa Elzanfaly \\ Faculty of Informatics and \\ Computer Science \\ The British University in Egypt \\ Helwan University \\ Cairo, Egypt \\ doaa.elzanfaly@bue.edu.eg
}

\begin{abstract}
The Internet-of-Things (IoT) technologies and cyber-physical systems has facilitated production monitoring and control. However, researches and applications still lack a standardized framework and an integrated technological solution that can maximize the leverage of real-time monitoring. This can be achieved through enabling data transfer and exchange between all entities/organizations in supply chains and accordingly utilizing the monitored data. This paper introduces a framework for production monitoring that utilizes and integrates ontological model, which implements and integrates Semantic Sensor Network (SSN) ontology with production monitoring services. In addition, Complex Event Processing is integrated in the proposed model to enable event patterns identification and undertake the appropriate (proactive) action accordingly. The framework is constructed based on ISA-95 and SCOR standards. The utility, applicability and efficacy of the proposed framework is validated by its application on a real-life large-scale case study in the domain of laser cutting machines.
\end{abstract}

\section{INTRODUCTION}

$\mathrm{I}^{\mathrm{N}}$ $\mathrm{N}$ manufacturing, it is crucial to ensure that production processes are ongoing without any problems. Accordingly, the manufacturing machines and used resources need regular monitoring to eliminate production losses in case of machines' unexpected breakdown or in case of producing final products with unacceptable quality. To avoid these problems traditional methods use human inspections [1] and planned regular machines maintenance [2]. However, Visual inspection is not sufficient; due to the limited detection range of observations [3]. In addition, relying on regular machine maintenance schedules might increase costs if machines are maintained prior to their need. On the contrary, it might not be detected that a machine needs earlier maintenance scheduling and would lead to machine break-down and significant losses.

The IoT technologies covers the previously mentioned gaps, through being able to monitor machines' conditions in a reliable and regular way [4]. As reported by Bera [5], one

This research is partially funded by the EC Horizon 2020 project ICP4Life, under contract number FoF-05-2014 - 636862

$\dagger$ Corresponding author, amal@servtech.info of the big industries that uses IoT devices is the 'manufacturing' industry; as it contributes by $40.2 \%$ from the different industries share in the IoT devices usage, in which the IoT devices are mainly used for robotic machinery control and fault diagnostics. In a survey carried out by Capgemini Digital Transformation Institute [6], it was found out that $57 \%$ out of $300+$ companies had problems with not having IoT standards for data sharing and interoperability to follow. In order to overcome this challenge, semantic technologies must be used according to [7], [8] and [9].

Enabling real-time production monitoring and allowing direct communication with service providers or entities in the supply chain, would result in efficient production plans. Therefore, the aim of this paper is to introduce an integrated framework that is founded on formal ontological domain models and integrates IoT technologies (mainly sensors) with production monitoring services. Furthermore, the proposed model integrates complex event processing [10] to utilize data collected and identify abnormal event patterns arising during the production process. A real-life large-scale case study that is conducted in the context of the H2020 ICP4Life ${ }^{1}$ project, is used to validate the usage, applicability and efficacy of the proposed framework and its implemented solutions.

The paper is divided as follows: In section (II), the background of IoT and ontologies is illustrated. In section (III), related work efforts are summarized. In section (IV), the used case study is demonstrated, while in section (V) the proposed framework is elaborated. Section (VI) includes implementation and evaluation details. Finally, section (VII) includes the conclusion and future work.

\section{BACKGROUND}

In order to efficiently integrate the IoT technologies, it is crucial to take advantage of the semantic technologies capabilities, specifically ontologies. In this section, we will illustrate shortly the capabilities, components and structure of (A) IoT (B) Ontologies.

\footnotetext{
${ }^{1}$ ICP4Life: http://www.icp4life.eu/
} 


\section{A. Internet-of-Things}

Internet-of-things (IoT) connects things/objects through the internet, through uniquely identifying each of the objects in the network and giving it the capability of communication with other objects/things. IoT architecture is composed of four main layers [4]: (i) sensor layer: which is concerned with all the physical devices involved to know the state of the object/thing, store its data or change its state. It includes sensors for collecting information about the object, as well as actuators for actuating on a specific object. It includes the RFID, that is responsible for storing data about the object. Additionally, this layer might include other devices used in data exchange and collection such as: smart phones, cameras, microphones, etc. (ii) network layer: which represents the means of data exchange throughout the network. (iii) service layer: This layer represents the means of services exchange (iv) interface layer: this layer represents the presentation/ displaying of the collected data to the endusers through different applications.

\section{B. Ontologies and Semantic Sensor Network Ontology}

As defined by Liu and Özsu [10], ontologies are used for the representation of knowledge in different domains by means of introducing the commonly used set of data or classes as well as their attributes. Moreover, they enable expressing the relationships between the different classes and their properties [10]. Ontologies are based on abstract representation of the data model, giving flexibility to separate the data models and the structures used or generally separating it from the implementation. Accordingly, the independence given to the data model in case of being used by an ontological model facilitates interoperability and standardization.

The Semantic Sensor Network (SSN) [11] is a standard ontology developed by $\mathrm{W} 3 \mathrm{C}$ for representing sensors, their observations and their applied context. Moreover, it describes actuators, actuations and their applied context. It will play a crucial role in the proposed model as it represents a standard representation for the IoT used components in sensing and actuating and the main classes and properties needed.

\section{LITERATURE REVIEW}

\section{A. Integration of Production Monitoring Systems and IoT}

There are several models proposed by different researches and SW companies that utilize IoT in production monitoring. Each of the models has a specific perspective and facilitates certain system's functionalities as illustrated below and summarized in Table I:

Ding, Jiang and $\mathrm{Su}$ [12]proposed social manufacturing system that facilitates real-time production and transportation monitoring and analysis. The system was based on the use of RFID and was evaluated by a printing machinery company. The system framework is divided into three layers: (i) Physical layer: which mainly contains RFID tags, readers and antennas. (ii) Application layer: which connects the manufacturing company with the customers and suppliers by the aid of service-oriented architecture concepts. In the conceptual model they defined two types of databases that should be implemented: Private databases and Public database. Each of the supply chain entities should have a private database to store their related real-time information, while the public database is meant to store the common information between the different entities. (iii) Social layer: this layer integrates the system with different social media apps, such as Facebook and twitter, as the medium of communication.

Mi and Kara [13] introduced a methodology to formulate a real-time manufacturing monitor application based on two steps. First, they defined how to design the architecture of the system. Second, they defined how to choose the components. They tested their methodology on a small-scale case study, in which they monitored the environment temperature of an office. Their focus of assessment was mainly considered with the possibility and ability to use Wireless Sensor Networks (WSN) with IoT.

Ding and Jiang [14] started their paper with describing how an IoT-enabled job-shop is configured and how the production can be integrated with the IoT. Then they proposed a data model for event-driven data collection and analysis. Finally, they evaluated their work through a simulated case study.

Lee, Noh, Kim and Kang [15] proposed an architecture framework for Cyber-Physical Production Systems which aims for predicting quality and control of production processes. The framework integrates IoT, production processes and AI and they tested it on actual plants. The framework is mainly composed of three sub-systems: (i) Big Data Analytics system: which is responsible for storing the produced data from the IoT tools and the data manipulated by the manufacturing system. Also, it uses different machine learning tools to produce business insights (ii) Detection and Coordination System: this system is used for handling different events (iii) KPI Simulation system: Based on the collected real-time information and the production plan, a simulation model was carried out and produced reference KPIs for the expected quality and productivity issues.

Ahmed et al. [16] proposed a conceptual model that uses fact-driven statistical methodology to analyze machines' failure factors and causes and further facilitate critical failures prediction. Their conceptual model is divided to three layers: (i) Sensory Devices layer (ii) Data Storing and Sharing layer (iii) User Interface layer.

\section{B. Ontological Models for Production/Manufacturing}

From another perspective, there are several trials for proposing ontologies for production monitoring, which will be illustrated below.

Cao, Zanni-Merk and Reich [17] proposed an ontology for condition-monitoring based on ISO standards, claiming that it is more generalized than the current available conditionmonitoring ontologies. They followed the iterative ontology development method, mentioned in [18], for developing the 
TABLE I.

RELATED WORK MODELS AND TECHNOLOGIES USED

\begin{tabular}{|c|c|c|c|c|c|}
\hline Paper & Area of Interest & $\begin{array}{c}\text { IoT } \\
\text { Technology }\end{array}$ & $\begin{array}{l}\text { Means of Integration } \\
\text { and Communication }\end{array}$ & Evaluation & Limitations \\
\hline \multirow[t]{2}{*}[12]{} & \multirow{2}{*}{$\begin{array}{l}\text { Real-time production } \\
\& \text { transportation } \\
\text { monitoring }\end{array}$} & \multirow[t]{2}{*}{ RFID } & Social Media & \multirow{2}{*}{$\begin{array}{l}\text { Printing } \\
\text { Machinery } \\
\text { Company }\end{array}$} & \multirow{2}{*}{$\begin{array}{l}\text { Each of the involved entities should have private } \\
\text { database with the defined data interface of the } \\
\text { model }\end{array}$} \\
\hline & & & $\begin{array}{l}\text { Service-Oriented } \\
\text { Architecture }\end{array}$ & & \\
\hline$[13]$ & $\begin{array}{l}\text { methodology to } \\
\text { formulate a real-time } \\
\text { manufacturing } \\
\text { monitor application }\end{array}$ & $\begin{array}{l}\text { Sensors and } \\
\text { RFID } \\
\text { integrated with } \\
\text { WSN }\end{array}$ & Cloud Platform & $\begin{array}{l}\text { Office } \\
\text { temperature } \\
\text { environment } \\
\text { monitoring }\end{array}$ & $\begin{array}{l}\text { The case study focused on the limitations and } \\
\text { abilities of usage of WSN and RFID in the } \\
\text { manufacturing company and did not proposed a } \\
\text { standardized interoperable model that would allow } \\
\text { data exchange with other entities/organizations } \\
\text { such a suppliers and customers }\end{array}$ \\
\hline$[14]$ & $\begin{array}{l}\text { IoT-enabled smart } \\
\text { job-shop production }\end{array}$ & $\begin{array}{l}\text { RFID antennas } \\
\text { readers, and } \\
\text { active tags }\end{array}$ & None & $\begin{array}{l}\text { Job-shop } \\
\text { production lab } \\
\text { simulation }\end{array}$ & $\begin{array}{l}\text { The gathered data is utilized inside the production } \\
\text { company only }\end{array}$ \\
\hline$[15]$ & $\begin{array}{l}\text { Cyber-Physical } \\
\text { production systems } \\
\text { monitoring and } \\
\text { control }\end{array}$ & $\begin{array}{l}\text { General tools } \\
\text { used not } \\
\text { mentioned } \\
\text { specifically }\end{array}$ & None & $\begin{array}{l}\text { Piston engine } \\
\text { factory }\end{array}$ & $\begin{array}{l}\text { The gathered data is utilized inside the production } \\
\text { company only }\end{array}$ \\
\hline$[16]$ & $\begin{array}{l}\text { Production critical } \\
\text { failure analysis }\end{array}$ & $\begin{array}{l}\text { Sensory } \\
\text { Devices }\end{array}$ & Cloud Platform & $\begin{array}{l}\text { Beverage } \\
\text { production } \\
\text { company } \\
\end{array}$ & $\begin{array}{l}\text { Lack of standardized approach for the exchanged } \\
\text { data manipulation by the different organizations. }\end{array}$ \\
\hline$[17]$ & $\begin{array}{l}\text { Condition monitoring } \\
\text { ontology }\end{array}$ & Sensors & Ontology & ISO standards & $\begin{array}{l}\text { The classes used in the ontology has limited scope } \\
\text { and do not fully integrated the IoT, Production } \\
\text { processes and collected data utilization }\end{array}$ \\
\hline [19] & $\begin{array}{l}\text { Smart product service } \\
\text { ontology }\end{array}$ & Sensors & $\begin{array}{l}\text { Cloud infrastructure } \\
\& \text { Ontology }\end{array}$ & $\begin{array}{l}\text { Laser cutting } \\
\text { machine } \\
\text { manufacturer }\end{array}$ & $\begin{array}{l}\text { The classes used in the ontology has limited scope } \\
\text { regarding the data collected utilization and the IoT } \\
\text { classes }\end{array}$ \\
\hline$[20]$ & $\begin{array}{l}\text { Intelligent conditional } \\
\text { monitoring ontology }\end{array}$ & - & Ontology & $\begin{array}{l}\text { Rotating } \\
\text { machinery }\end{array}$ & $\begin{array}{l}\text { The classes used in the ontology has limited scope } \\
\text { and do not fully integrated collected data utilization } \\
\text { and IoT }\end{array}$ \\
\hline
\end{tabular}

ontology. Its core classes include: System, State, Process, Parameter, Sensor, Fault, Failure and Behavior.

In an earlier work related to ICP4Life project, Maleki et al. [19] presented a framework that enables products' customizing services by the aid of sensor ontology and this was validated by using an industrial use case.

Cao et al. [20] proposed an intelligent conditional monitoring ontology. It includes the main classes of production processes and faults handling, but it ignores classes related to the IoT technology.

As a consequence of checking the available related work and the proposed models, it was found that none of them provide an interoperable standardized solution that can allow knowledge sharing through different organizations. Moreover, those models do not allow subsequent utilization of the gathered and exchanged data through using analytics or event patterns identification.

\section{CASE STUdy}

The case study is carried out for turbine engine manufacturer, which is in our context the entity that needs production monitoring for laser cutting machines used in production. In related work [21] of the H2020 ICP4Life project, the objectives were concerned with co-designing and specifying the machine components and design according to the user's (turbine engine manufacturer) requirements. However, in the scope of the paper context, the objective is to utilize sensors added to the machine and to ensure data unification, to facilitate and enable data exchange with the service provider.

The user uses a web application to customize the product's sensors related to the required after-sales services. Furthermore, the user monitors the information collected by the sensor using dynamic charts and is altered through the system in case of exceeding a primary determined threshold for the sensor readings, as shown in figure 2. For instance, the user can choose the temperature sensor for the monitoring and control service by dragging a 2-D image that represents the sensor and service in addition to the main components used in the laser cutting machine composition as shown in figure1. When the machine is working, the temperature changes recorded by the sensor will be reflected on the screen as shown in figure2.

The manufacturing blueprint concept introduced by [22] is used to ensure having a smart manufacturing network through cross-functional integration and communication. 




Fig. 1 Product Service Systems Customized after Sensors customization addition to the solution proposed in [23]



Fig. 2 Temperature Monitoring and Notification

\section{V.PROPOSED FRAMEWORK}

Reviewing the main modules involved in product-service systems (PSS) stated by [23], which are: (i) PSS requirements elicitation. (ii) PSS configuration and customization (ii) Production planning (iii) Production execution. (iv) Production Monitoring, we will capitalize our proposed work in this paper on the production monitoring requirements.

The main objective is to propose a reliable framework that enables real-time production monitoring and allows direct communication with the supply chain entities. Accordingly, the proposed framework is composed of four layers to meet the required objective as shown in figure 3 .

\section{A. Data Collection Layer}

The first layer in the framework, is the 'Data Collection Layer' and it includes all the tools used to collect the data related to the machines' conditions and to the attributes that affect the product quality. It mainly contains all the IoT hardware such as sensors, readers, cameras, microphones. The needed hardware is determined according to the monitoring criteria. They are mainly installed in the machine context and their data is shared between the manufacturer and service provider. For example, in the case study temperature sensors where added to the cutting laser machine to measure the environmental conditions.

\section{B. Data Storage \& Management Layer}

The data storage layer ensures two aspects: The interoperability and the data sharing. Storing the data in a data center that is accessible by all interested parties would facilitate communication. However, exchanging data that is meaningful and understandable needs a standardized approach. Accordingly, to unify data, the data storage \& management layer are based on ontology or the blueprints concept [22].

There are three main levels of ontology that form a hierarchy: (i) The Top-level ontology: which It defines the general terms, entities and their relationships. The main feature of top-ontology is that it can be implemented in several domains e.g. Semantic Sensor Network (SSN) ontology, as it includes the main classes related to the sensor network without defining the context or domain that they will be integrated in. (ii) The domain-level ontology: It defines entities, attributes and relationships related to a specific domain, which in our case will be the cutting-laser machines domain. The most common sensors involved in the observation of cutting laser machines will be added as subclasses of the sensor class. (iii) The application-level ontology: It contains the actual instances instantiated from the domain ontology in the running application. In the context of the case study, the actual sensor used for monitoring temperature is added as instance from the temperature sensor class.

Top-Ontology/Blueprints:

[22] introduced five main blueprints related to the manufacturing scope:

- Partner/Stakeholder Blueprint: It is mainly concerned with the knowledge related to the partner's company, its details and capabilities.

- Product Blueprint: It contains knowledge related to the product, its materials, needed resources, components and properties.

- Product-Service: It focuses on the after-sale services needed for the product such as machine maintenance and upgrades.

- Production-Plan Blueprint: It describes the process flow, involved activities and resources for actual production.

- Quality Assurance Blueprint: KPIs metrics and the knowledge needed to ensure that the product's and machine's quality are reflected in this blueprint.

In the context of our framework objectives, four main ontologies are integrated to the SSN ontology to reach the objective of the proposed framework.

- Service Blueprint: The product service blueprint proposed by [22] is extended to integrate the appropriate classes from the SSN, which facilitates providing related services such as production monitoring and control. Primarily, the customer determines the needed services for their resources 


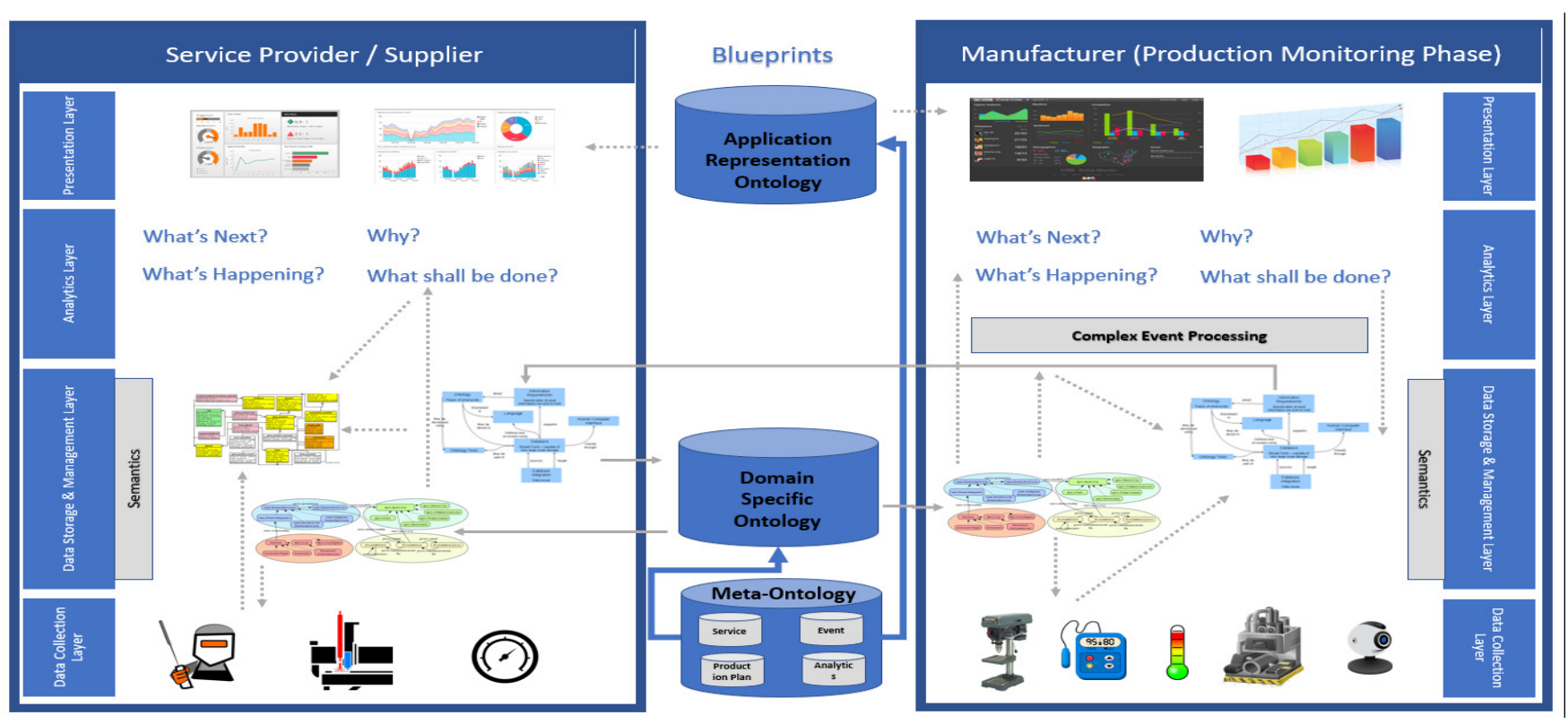

Fig. 3 Proposed Framework

(products) and then accordingly, the sensors are determined. Finally, the observation process takes place. Some examples of the classes included in the blueprint are: (i) Service: It describes the service. (ii) Service provider: It represents the entity that provide the service. (iii) Customer: It represents the customer who requests the customized service. (iv) Sensor: It is one of the main classes integrated from the SSN as the sensor determination will be determined based on the service.

- Event Blueprint: It represents the entities used in detecting and monitoring events. Event tracking is facilitated after the integration of sensors, as they enable collecting real-time data and identifying abnormal patterns. An example of the classes included in the blueprint: (i) Event class: It represents the event. (ii) Listener class: It represents the class that listens to the result and act accordingly by comparing the readings to the thresholds. (iii) Event handler class: It acts upon managing how the event and its readings are managed with subscribers or listeners

- Production Blueprint: It describes the production processes and their segments. It also describes the needed resources and production processes monitoring rules. Examples of included classes: (i) Process Segment: Which includes the main steps carried out to perform specific process. (ii) Production rules: Which states the constrains and rules related to the production process. (iii) Product segment: It is the overlap definition between the production rules and the bill of resources (required resources) which are defined in the segment requirements. (iv) Resources: Which are the resources involved in the production process.
- Analytics Blueprint: It represents the classes needed for analyzing the collected data and results. In the current scope, it only includes the possible actions that could be taken after a specific event pattern detection. There are three main types of action: (i) Descriptive action: Which is just descriptive for the situation in the form of alert or message notification with the result. (ii) Predictive action: Which applies predictive model on the collected data to reach specific insight. (iii) Actuator action: Which represents the action that should be carried out by an actuator.

- Production Monitoring Blueprint: It represents the means of integration and relationships representation between the main classes used from each of the previous blueprints. The blueprint is shown in figure 4 and is demonstrated shortly in the upcoming paragraph.

Using the product production rules, the monitoring rules are determined, which describes the needed observable property and defines the needed listeners based on the threshold. The listeners listen to the event results of the observations made by the sensors. If the listener detects a specified abnormal pattern of events, an appropriate action is triggered. The action can either be informative, in which it describes what has happened in terms of sending warning or notification, or the action can be actuatable action, which is an action that triggers a specific actuator to act on specific actuatable property, or the action can be predictive action.

An example of the instantiated individuals from the blueprint in the case study is as follows:

The monitoring rule specify that the temperature cannot exceed 40 degree Celsius and there should 


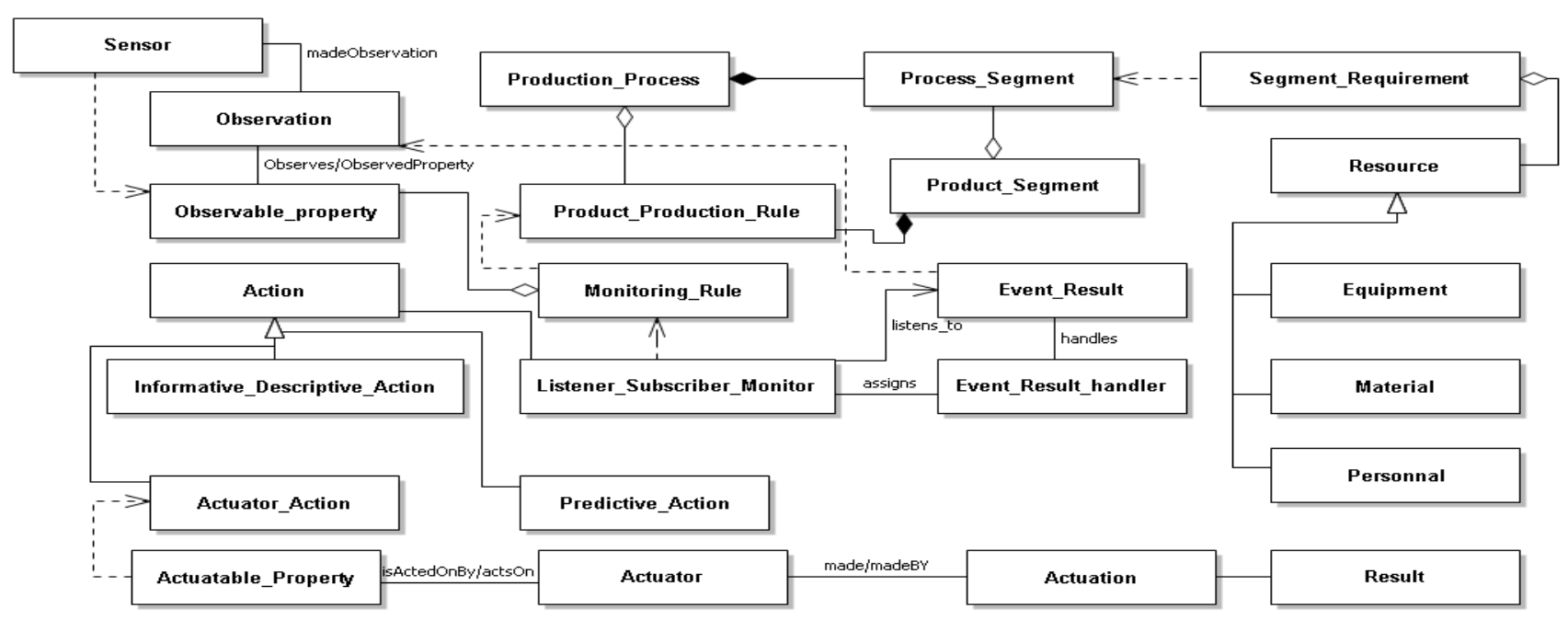

Fig. 4 Production Monitoring Blueprint

not be increase in temperature in 3 consequent readings by more than $0.1 \%$. Accordingly, it is determined that machine temperature is set as observable property and temperature sensor is needed. The observations' results will be listened to by the listener to detect any matching pattern with the threshold and restrictions. In case of pattern detection, an informative action is taken through sending warning on the application screen.

\section{Domain Specific Ontology:}

The classes are customized depending on the domain context. For example: In case of the context of cutting laser machine, the cutting laser machine class will extend class equipment.

Application Representation Ontology:

Introducing a domain-ontology for a specific context like the laser cutting machines allows interoperability and knowledge sharing between different entities. However, if we need to map the process that sends data to the front-end dynamically, each organization should develop its own customization terms, to link the back-end data to the frontend display. To facilitate this process, we propose the 'Application Representation Ontology'. The Application Representation Ontology is responsible for defining how the instances created shall be displayed. For example, to display the temperature sensor, it can include the displaying picture, location and dimensions of picture on the screen, the color of the surrounding frame and so on. This would allow the instances and their display properties to be read directly from the blueprints and displayed to the end-user.

Data Exchange between different entities using blueprints:

After the data is collected (at the manufacturer side) with the IoT tools the data is mapped to the domain ontology and the instances are created based on the data, the relative instances are sent to (the Service Provider). At the Service Provider the instances are compared against the domain Specific ontology and save its instances accordingly.

\section{A. Complex Event Processing}

As illustrated by [10], complex event processing is about detecting event patterns in real-time through monitoring the input data and listening to it. Then, in case of matching a pattern sequence an appropriate action is taken. It is used in the model as a main component for detecting event patters and acting correspondingly.

\section{B. Analytical Layer}

The analytical layer utilizes the collected data through demonstrating and justifying what has happenedpredicting what will happen and can also recommend the possible proactive action. This is reached by implementing descriptive, diagnostic, predictive and prescriptive analytics.

\section{Presentation Layer}

The presentation layer is the gateway for presenting the collected data and gained knowledge to the end users (stakeholders). It may include dashboards, managerial reports and user-friendly GUIs for data representation and production system control.

\section{IMPLEMENTATION AND EVALUATION}

To ensure the reliability of our model: (i) Related standards were considered, which are ISA-95 and SCOR (ii) A standard ontology to represent the IOT classes integration was used, which is the SSN proposed by W3C. (iii) Limitations detected in other ontologies proposed by researches were overcame. (iv) The guidelines of how to create ontologies and the carried-out steps stated by [18] were followed. (v) The case study illustrated in section IV was carried in manufacturing cutting laser machines domain.

In the case study, the following procedures were carried out during implementation: 


\section{A. Creating Instances}

Instances of the ontology/blueprint were created and stored using 'Protégé' ontology editor [24]. Example of created instances are shown in Table II and Figure 5:

TABLE II.

Created Instances Example

\begin{tabular}{|l|l|l|}
\hline $\begin{array}{c}\text { Meta-Ontology } \\
\text { Level Class }\end{array}$ & Domain Level Class & $\begin{array}{l}\text { Instantiated } \\
\text { Individual }\end{array}$ \\
\hline Product & $\begin{array}{l}\text { Cutting Laser } \\
\text { Machine }\end{array}$ & $\begin{array}{l}\text { Cutting Laser } \\
\text { Machine Type A }\end{array}$ \\
\hline Product Component & Lens & Lens X \\
\hline Event & Temperature Event & $\begin{array}{l}\text { Temperature Event } \\
\text { A }\end{array}$ \\
\hline Product Segment & Cutting Laser & $\begin{array}{l}\text { Co2 Cutting Laser } \\
\text { Machine Product } \\
\text { Segment }\end{array}$ \\
\hline Sensor & Segment & $\begin{array}{l}\text { Temperature } \\
\text { Sensor A }\end{array}$ \\
\hline
\end{tabular}

\section{B. Ability of Reading and Writing Instances (Manipulating Blueprints)}

As the target of the blueprints is to have a common knowledge model that enables data unification and exchange, creating instances from blueprints as well as manipulating them is essential. Reading and writing from the blueprints is carried out by the aid of Jena, a java library, which enables reading/writing from/in ontology files.

However, in order to make the process self-dependent of accessing blueprints until displaying content of the system. We recommend having a fourth ontological layer, above the third layer of instances to contain the main ontological classes needed in the display of the instances. For example, the GUI data properties that are specified for the temperature sensor includes the filling shape, the location at the screen, the color of the displayed picture, etc.

\section{Used Scenario and Instances for Simulation}

Using the Monitoring rules, it is determined that the temperature event of the surrounding environment of the machine needs to be monitored. Accordingly, the observable property is determined to be the temperature. Moreover, the temperature sensor is used for the observation. The listener listens to the results and according to the production rules, it compares the results pattern to the identified threshold. When the listener identifies abnormal patterns, an appropriate action is taken. In our system we have simulated the 'informative_descriptive_action' and a warning notification is sent. The prototype was implemented using a web app developed on Eclipse Jee Mars, version (4.5.2). Tomcat Server V8.0 was used. To handle back-end and front-end synchronization, AJAX was used aside from Jsp, java, HTML and JavaScript.

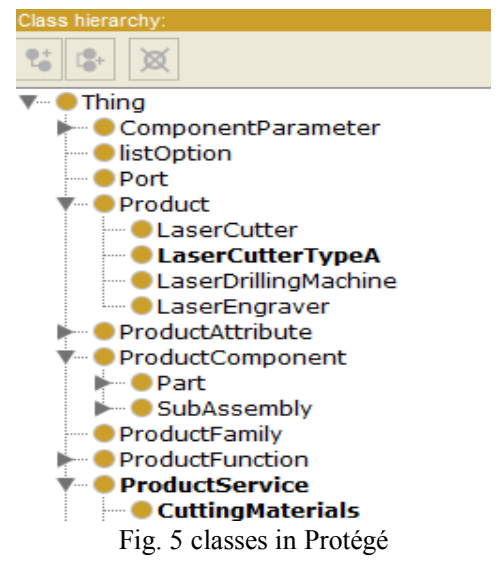

\section{Discussion}

The proposed model and system were able to provide an ontological model for production monitoring and mainly cutting laser machines domain. The data was saved and retrieved with reference to the model. The system enabled utilizing the data collected through complex event processing, which identifies abnormal patterns. Accordingly, the system was able to cover the gaps found in the other related works as seen in Table III.

TABLE III.

COMPARISON BETWEEN THE PREVIOUS MODELS AND THE PROPOSED MODEL

\begin{tabular}{|l|l|l|l|l|}
\hline Paper & $\begin{array}{c}\text { Monitoring } \\
\text { using IoT } \\
\text { technologies } \\
\text { cation \& } \\
\text { Data } \\
\text { Exchange }\end{array}$ & $\begin{array}{c}\text { Means of } \\
\text { Communi- }\end{array}$ & $\begin{array}{l}\text { Interop- } \\
\text { erability }\end{array}$ & \multicolumn{1}{|c|}{$\begin{array}{c}\text { Utilizing } \\
\text { collected } \\
\text { data / } \\
\text { Analysis }\end{array}$} \\
\hline$[12]$ & Yes & Yes & No & Yes \\
\hline$[13]$ & Yes & Yes & No & No \\
\hline$[14]$ & Yes & No & No & Yes \\
\hline$[15]$ & Yes & No & No & Yes \\
\hline$[16]$ & Yes & Yes & No & Yes \\
\hline$[17]$ & Yes & Yes & Yes & No \\
\hline$[19]$ & Yes & Yes & Yes & No \\
\hline$[10]$ & No & Yes & Yes & Yes \\
\hline $\begin{array}{l}\text { Proposed } \\
\text { Model }\end{array}$ & Yes & Yes & Yes & Yes \\
\hline
\end{tabular}

\section{CONCLUSION AND FUTURE WORK}

This paper aims to provide efficient framework for production monitoring based on domain ontologies and IoT utilization. Accordingly, the proposed contribution of the paper is threefold: (i) It defines the main layers needed for an integrated framework that enables real-time monitoring through using IoT technologies. In addition, it ensures data unification through an ontological model for data exchange. Moreover, it utilizes the collected data through integrating 
complex event-processing for abnormal events detection and supports the monitoring process via a presentable GUI. (ii) It proposes an ontological model for production monitoring based on the blueprints' concepts introduced in [22] and the ISA-95 standards [25]. (iii) It introduces 'Application Representation Ontology' as a fourth level of ontologies mapping to define the means of displaying ontology's individuals in applications and systems. A case study was applied in the cutting laser machines domain for framework applicability evaluation.

Current and future work efforts are in diverse directions related to Manufacturing and Blueprints Concepts. However, a main focus for the consequent work related to the proposed work in this paper, is the utilization of real-time data using analytics by the aid of ontology reasoning. Business Analytics will not only facilitate predicting crucial production concepts, but also will enable reaching a proactive approach that will make the production leaner. In another direction, the blueprints are to-be enhanced and extended in an iterative manner, to make use of industry 4.0 capabilities and technologies.

\section{VIII.ACKNOWLEDGEMENT}

We wish to thank PRIMA INDUSTRIE S.p.A. (https://www.primaindustrie.com/) for providing the essentials of the pilot study in this paper. Special thanks go to Dr. Indika Priyantha, Jheronimus Academy of Data Science, the NL, for contributing to the development of the tool-suite. The authors are grateful to engineers José Luis Ajuria and Ion Ruiz at SEGULA Tecnologias España for their contributions to the $3 \mathrm{D} \mathrm{CAD} / \mathrm{CAM}$ capabilities of the tool-suite.

\section{REFERENCES}

[1] P. Foster, "Manufacturing Quality Control: The Difference Between Product and Process Audits," Beacon Quality, 2018. [Online]. Available: https:/www.beaconquality.com/blog/manufacturingquality-control-the-difference-between-product-and-process-audits. [Accessed: 23-Apr-2019].

[2] M. Ardolino et al., "The role of digital technologies for the service transformation of industrial companies," Int. J. Prod. Res., vol. 7543, no. May, 2017. DOI: https://doi.org/10.1080/00207543.2017.1324224

[3] V. Chaudhary, I. R. Dave, and K. P. Upla, "Automatic visual inspection of printed circuit board for defect detection and classification Automatic Visual Inspection of Printed Circuit Board for Defect Detection and Classification," in 2017 International Conference on Wireless Communications, Signal Processing and Networking (WiSPNET), 2017.

DOI: https://doi.org/10.1109/WiSPNET.2017.8299858

[4] M. Riad, A. Elgammal, and D. ElZanfaly, "Efficient Management of Perishable Inventory by Utilizing IoT," in 2018 IEEE International Conference on Engineering, Technology and Innovation (ICE/ITMC), 2018. DOI: https://doi.org/10.1109/ICE.2018.8436267

[5] A. Bera, "80 Mind-Blowing IoT Statistics (Infographic)," 2019. [Online]. Available: https://safeatlast.co/blog/iot-statistics/. [Accessed: 25-May-2019].

[6] Capgemini D. T. Institute, "Unlocking the business value of IoT in operations," 2018.

[7] S. Dupont, A. Achour, L. Deru, and N. Matskanis, "Bringing Dynamics to IoT Services with Cloud and Semantic Technologies
An Innovative Approach for Enhancing IoT based Services," in IoTBD 2016 - International Conference on Internet of Things and Big Data, 2016, pp. 185-190. https://doi.org/10.5220/0005933001850190

[8] I. Szilagyi and P. Wira, "Ontologies and Semantic Web for the Internet of Things - A Survey," in 42nd IEEE Industrial Electronics Conference,

$$
2016 .
$$

https://doi.org/10.1109/IECON.2016.7793744

[9] M. Ganzha, M. Paprzycki, W. Pawłowski, P. Szmeja, and K. Wasielewska, "Semantic technologies for the IoT - an Inter-IoT perspective," in 2016 IEEE First International Conference on Internet-of-Things Design and Implementation (IoTDI), 2016. DOI: https://doi.org/10.1109/IoTDI.2015.22

[10] T. Rohrmann, "Introducing Complex Event Processing (CEP) with Apache Flink." 2016.

[11] W3C, "Semantic Sensor Network Ontology." Spatial Data on the Web Working Group, 2017.

[12] K. Ding, P. Jiang, and S. Su, "RFID-enabled social manufacturing system for inter-enterprise monitoring and dispatching of integrated production and transportation tasks," Robot. Comput. Manuf., vol. 49, no. 2018, pp. 120-133, 2017. DOI: https://doi.org/10.1016/j.rcim.2017.06.009

[13] W. Li and S. Kara, "Methodology for Monitoring Manufacturing Environment by Using Wireless Sensor Networks ( WSN ) and the Internet of Things ( IoT )," in The 24th CIRP Conference on Life Cycle Engineering Methodology, 2017, vol. 61, pp. 323-328. DOI: http://dx.doi.org/10.1016/j.procir.2016.11.182

[14] Kai Ding and P. Jiang, "RFID-based Production Data Analysis in an IoT-enabled Smart Job-shop," IEEE/CAA J. Autom. Sin., vol. 5, no. 1, pp. 1-11, 2018. DOI: https://doi.org/10.1109/JAS.2017.7510418

[15] J. Lee, S. Do Noh, H. Kim, and Y. Kang, "Implementation of CyberPhysical Production Systems for Quality Prediction and Operation Control," Sensors, vol. 18, no. 1428, 2018. DOI: $10.3390 / \mathrm{s} 18051428$

[16] S. Ahmad, A. Badwelan, A. M. Ghaleb, A. Qamhan, and M. Sharaf, "Analyzing Critical Failures in a Production Process : Is Industrial IoT the Solution?," Wirel. Commun. Mob. Comput., vol. 2018, 2018. DOI: https://doi.org/10.1155/2018/6951318

[17] Q. Cao, C. Reich, and P. Afonso, "Towards a Core Ontology for Condition Monitoring," in Procedia Manufacturing, 2019, vol. 28, pp. 177-182. DOI: https://doi.org/10.1016/j.promfg.2018.12.029

[18] N. F. Noy and Deborah L. McGuinness, "Ontology Development 101: A Guide to Creating Your First Ontology.” [Online]. Available: https://protege.stanford.edu/publications/ontology_development/onto logy101-noy-mcguinness.html. [Accessed: 25-Apr-2019].

[19] E. Maleki et al., "Ontology-based framework enabling smart Product-Service Systems: Application of sensing systems for machine health monitoring," IEEE Internet Things J., vol. 2327, no. 4662, 2018. DOI: https://doi.org/10.1109/JIOT.2018.2831279

[20] Q. Cao, F. Giustozzi, C. Zanni-merk, F. D. B. De, and C. Reich, "Smart Condition Monitoring for Industry 4.0 Manufacturing Processes : An Ontology-Based Approach," Cybern. Syst. an Int. J., 2019. DOI: https://doi.org/10.1080/01969722.2019.1565118

[21] D. Bogataj, M. Bogataj, and D. Hudoklin, "Mitigating risks of perishable products in the cyber-physical systems based on the extended MRP model," Int. J. Prod. Econ., vol. 193, no. April 2016, pp. 51-62, 2017. DOI: https://doi.org/10.1016/j.ijpe.2017.06.028

[22] M. P. Papazoglou and A. Elgammal, "The Manufacturing Blueprint Environment: Bringing Intelligence into Manufacturing," in 23rd ICE/IEEE International Technology Management Conference, 2017, pp. 772-781. DOI: 10.1109/ICE.2017.8279960

[23] M. P. Papazoglou, A. Elgammal, and B. J. Krämer, "Collaborative on-demand Product-Service Systems customization," CIRP J. Manuf. Sci. Technol., $2018 . \quad$ DOI: https://doi.org/10.1016/j.cirpj.2018.08.003

[24] BMIR, "Protégé." [Online]. Available: https://protege.stanford.edu/.

[25] ISA, "ISA-95.00.01-CDV3 Enterprise-Control," pp. 1-165, 2008. 